\title{
Correction to: Quantifying the Uncertainty Interaction Between the Model Input and Structure on Hydrological Processes
}

\author{
Shuai Zhou ${ }^{1} \cdot$ Yimin Wang ${ }^{1} \cdot$ Ziyan $^{\mathrm{Li}^{1}} \cdot$ Jianxia Chang ${ }^{1} \cdot$ Aijun Guo $^{1}$ \\ Published online: 6 September 2021 \\ (c) Springer Nature B.V. 2021
}

\section{Correction to: Water Resour Manag} https://doi.org/10.1007/s11269-021-02883-7

In this article the affiliation details for Author Yimin Wang was incorrectly given as 'Xian University' but should have been 'Xi' an University of Technology'. The original article has been corrected.

Publisher's Note Springer Nature remains neutral with regard to jurisdictional claims in published maps and institutional affiliations.

The original article can be found online at https://doi.org/10.1007/s11269-021-02883-7.

Yimin Wang

wangyimin@xaut.edu.cn

1 State Key Laboratory of Eco-Hydraulics in Northwest Arid Region of China, Xi' an University of Technology, Xi'an, China 